\title{
Challenges in the uptake of telemedicine in dentistry
}

\author{
M Estai, E Kruger, M Tennant, S Bunt, Y Kanagasingam \\ School of Anatomy, Physiology and Human Biology, University of Western Australia, Crawley, \\ Western Australia, Australia
}

Submitted: 11 February 2016; Revised: 26 September 2016; Accepted: 3 October2016; Published: 28 November 2016

\author{
Estai M, Kruger E, Tennant M, Bunt S, Kanagasingam Y \\ Challenges in the uptake of telemedicine in dentistry \\ Rural and Remote Health 16: 3915. (Online) 2016
}

Available: http://www.rrh.org.au

\section{A B S T R A C T}

With the availability of oral care services very unevenly distributed in rural or remote areas, underserved people seek oral care from non-dental care providers. Against this backdrop, and coupled with the decreasing cost of and innovations in technology, there is a growing interest in the adoption of telemedicine services. Regardless of the lack of good-quality evidence supporting the costeffectiveness of telemedicine, evidence already indicates that telemedicine, even with extra costs, helps in reducing the inequalities in the provision of primary health care. Telemedicine has the potential to overcome geographical barriers and contribute to closing the rural-urban healthcare gap in Australia and many other regions. Although research examining different teledentistry applications has found that this technology can be successfully integrated into different settings, there is little active teledentistry practice in Australia. The integration of telemedicine into the mainstream oral health system is a complex and collaborative process in which numerous factors at individual, infrastructure and organisational levels are involved. Addressing the barriers that delay the implementation of a teledentistry service can provide valuable insights into its lack of acceptance and establish an evidence base that can help to inform future decisions about the benefits of teledentistry.

Key words: acceptance, Australia, barriers, evidence, oral health, teledentistry.

\section{Context}

Although the average dentist-to-population ratio has increased over recent decades, a significant discrepancy between the ratio in urban and rural regions still exists ${ }^{1}$. With the availability of oral care services very unevenly distributed in regional and remote/very remote areas, underserved people seek oral care from non-dental care providers, most commonly physicians, hospital emergency departments or pharmacies ${ }^{2-4}$. Non-dental 
care providers often help to provide symptomatic relief and/or issue a referral to a dentist rather than providing effective dental $\operatorname{care}^{2,3}$.

Short-term measures such as relying on visiting services or volunteerism to overcome the lack of dental services in underserved areas can help but are often only temporary solutions. We need to look for long-term and systematic approaches for an ongoing solution. Against this backdrop and coupled with the decreasing cost of and innovations in information and communication technology (ICT), there is growing interest in the adoption of telemedicine services ${ }^{5}$. Teledentistry is a form of telemedicine that is specifically dedicated to dentistry that uses electronic medical records, ICT and the internet to provide consultation at a distance ${ }^{6}$. It is an innovative method of health service delivery that has the potential to facilitate timely distribution of information to locally based practitioners for better decision making, effectively triage patients who require referrals and support locally based treatment ${ }^{7,8}$. This strategy allows the underserved population to seek treatment earlier, provide access to specialist care and minimise the burdens of patients/parents who would have to travel long distances to receive consultations. The potential advantages of teledentistry are summarised in Table 1.

The history of teledentistry can be traced back to the 1990s, when the US Army established the first teledentistry project, Total Dental Access, within the Department of Defense, which enabled the referring general dentists located in a dental clinic at a military base to consult with dental specialists at a distance'. Ever since, the number of teledentistry projects has rapidly increased, particularly in the USA, Europe, Australia and Brazil $^{10}$. Despite growing interest in this technology, there has been a relatively slow integration of telemedicine into the mainstream oral health system. This can be attributed to the fact that many teledentistry projects are still ongoing or in proof-of-concept stages $^{10}$. In the past decade, the Alaskan Native Tribal Health Consortium in partnership with the University of Washington established a telemedicine-based workforce model with a long-term strategy that centres on developing and training dental health aide therapists in Alaska to provide essential dental care, utilising telemedicine, to Alaskan residents under indirect supervision by dental experts ${ }^{11,12}$.

Two different technological approaches are used in telemedicine applications: real-time and store-and-forward technology. Although teledentistry services are still largely utilised in real time $^{10}$, store-and-forward teledentistry has proven to be more cost-saving and efficient compared to real-time and in-person care approaches ${ }^{4,13,14}$. Previous studies have not provided any evidence that telemedicine interventions are cost-effective when compared with non-telemedicine care approaches ${ }^{15,16}$. Most research reports have indicated that the absence of evidence supporting the costeffectiveness and effectiveness of telemedicine creates a barrier to its implementation within routine healthcare services. Costanalysis studies of telemedicine are often pragmatic and mainly concerned with costs and their minimisation while ignoring equity issues of access to health care. Regardless of head-to-head economic benefits, evidence already indicates that telemedicine, even with its potential extra costs, can help in reducing inequalities in oral health ${ }^{17}$.

\section{Issues}

Despite its enormous potential, several constraints for the growth and acceptance of teledentistry do exist (Table 2). The successful implementation of a sustainable telemedicine model is a complex and collaborative process involving numerous factors at individual, infrastructure and organisational levels ${ }^{18}$. Although perceived usefulness and ease of use are essential factors in the acceptance of any technology ${ }^{19}$, there is very little published evidence regarding patient readiness and acceptance of teledentistry services ${ }^{20}$. The body of literature on the acceptance of teledentistry is limited to care providers $^{\prime 21-25}$ or end-users ${ }^{126}$ perceptions of this technology. Further research is needed to examine in depth the patient's acceptance of teledentistry. Other considerations such as nontechnological, political or organisational barriers (planning, bureaucratic difficulties, lack of reimbursement guidelines, and medico-legal and copyright issues) have not been well investigated in the literature ${ }^{27,28}$. Such issues may become more evident when the practice of teledentistry becomes more widespread, highlighting the need for creating new laws to regulate the practice of teledentistry. 


\section{Table 1: Benefits of teledentistry}

\begin{tabular}{|c|c|}
\hline Level & Benefits \\
\hline Patient & $\begin{array}{l}\text { - } \\
\text { - } \\
\text { - } \\
\text { - Illows reception of a timely diagnosis and follow-up appointment } \\
\text { - } \\
\text { - }\end{array}$ \\
\hline Societal & $\begin{array}{ll}\text { - } & \text { Minimises burdens of parents or caregivers missing work } \\
\text { - } & \text { Reduces frequency of missed school days } \\
\text { - } & \text { Reduces inequity and inequalities in oral health in the community } \\
\text { - } & \text { Addresses specific needs of underserved populations }\end{array}$ \\
\hline
\end{tabular}

Table 2: Barriers to the uptake of teledentistry

\begin{tabular}{|c|c|}
\hline Level & Barriers \\
\hline Individual & $\begin{array}{l}\text { - } \text { Lack of research on patient's acceptance of teledentistry services } \\
\text { - } \quad \text { Poor levels of IT literacy } \\
\text { - } \\
\text { - } \quad \text { Lesistance to new technologies } \\
\text { - } \quad \text { Concerns direct patient contact } \\
\text { - } \quad \text { Concerns with decline in the accuracy and quality of health information } \\
\text { - } \quad \text { Increased clinical workload and consultation time } \\
\text { - } \quad \text { Increased costs and practice expense }\end{array}$ \\
\hline Infrastructural & 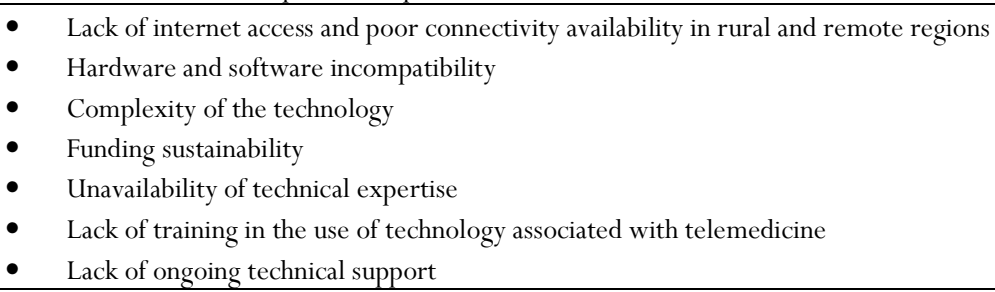 \\
\hline Organisational & 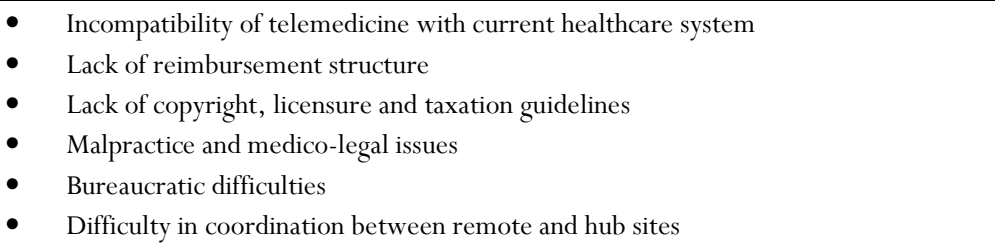 \\
\hline
\end{tabular}




\section{Lessons learned}

The shortcomings in existing policy and practice may indicate that the use of teledentistry does not receive support by healthcare policy-makers due to lack of evidence related to the cost-effectiveness of teledentistry in head-to-head comparisons $^{29}$. Addressing the barriers that delay the implementation of teledentistry services can provide a valuable insight into its acceptance and establish an evidence base that can help to inform future decisions about the benefits of teledentistry. Both strong political support and adoption of new legislations are essential to bring the underserved population up to an acceptable level of oral health and reduce the inequalities in oral health status between those who live in rural areas and in general populations.

\section{References}

1. Tennant M, Kruger E. A national audit of Australian dental practice distribution: do all Australians get a fair deal? International Dental Journal 2013; 63(4): 177-182. http://dx.doi.org/10.1111/ idj. 12027

2. Maunder P, Landes D. An evaluation of the role played by community pharmacies in oral healthcare situated in a primary care trust in the north of England. British Dental Journal 2005; 199(4): 219-223. http://dx.doi.org/10.1038/sj.bdj.4812614

3. Cohen LA, Bonito AJ, Eicheldinger C, Manski RJ, Macek MD, Edwards RR, et al. Comparison of patient visits to emergency departments, physician offices, and dental offices for dental problems and injuries. Journal of Public Health Dentistry 2011; 71(1): 13-22. http://dx.doi.org/10.1111/j.1752-7325.2010.00195.x

4. Okunseri C, Pajewski NM, Jackson S, Szabo A. Wisconsin Medicaid enrollees' recurrent use of emergency departments and physicians' offices for treatment of nontraumatic dental conditions. Journal of the American Dental Association 2011; 142(5): 540-550. http: / /dx.doi.org/10.14219/jada.archive.2011.0224
5. Moffatt JJ, Eley DS. The reported benefits of telehealth for rural Australians. Australian Health Review 2010; 34(3): 276-281. http://dx.doi.org/10.1071/AH09794

6. Fricton J, Chen H. Using teledentistry to improve access to dental care for the underserved. Dental Clinics of North America 2009; 53(3): 537-548. http://dx.doi.org/10.1016/j.cden.2009.03.005

7. Mariño R, Clarke K, Manton DJ, Stranieri A, Collmann R, Kellet $\mathrm{H}$, et al. Teleconsultation and telediagnosis for oral health assessment: an Australian perspective. In: S Kumar (Ed). Teledentistry. Cham: Springer International Publishing, 2015; 101 112.

8. Estai M, Kruger E, Tennant M. Optimizing patient referrals to dental consultants: implication of teledentistry in rural settings. Australasian Medical Journal 2016; 9(7): 249-252.

9. Rocca MA, Kudryk VL, Pajak JC, Morris T. The evolution of a teledentistry system within the Department of Defense. Proceedings of the AMIA Symposium 1999; 921-924.

10. Mariño R, Ghanim A. Teledentistry: a systematic review of the literature. Journal of Telemedicine and Telecare 2013; 19(4): 179-183.

11. Wetterhall S, Burrus B, Shugars D, Bader J. Cultural context in the effort to improve oral health among Alaska Native people: the dental health aide therapist model. American Journal of Public Health 2011; 101(10): 1836-1840. http://dx.doi.org/10.2105/AJPH. 2011.300356

12. Williard ME, Fauteux N. Dentists provide effective supervision of Alaska's dental health aide therapists in a variety of settings. Journal of Public Health Dentistry 2011; 71(Suppl 2): 27-33. http://dx.doi.org/10.1111/j.1752-7325.2011.00266.x

13. Butler TN, Yellowlees P. Cost analysis of store-and-forward telepsychiatry as a consultation model for primary care. Telemedicine Journal and e-Health 2012; 18(1): 74-77. http://dx.doi.org/ $10.1089 /$ tmj. 2011.0086 
14. Mariño R, Tonmukayakul U, Manton D, Stranieri A, Clarke K. Cost-analysis of teledentistry in residential aged care facilities. Journal of Telemedicine and Telecare 2016; 22(6): 326-332. http:// dx.doi.org/10.1177/1357633X15608991

15. Whitten PS, Mair FS, Haycox A, May CR, Williams TL, Hellmich S. Systematic review of cost effectiveness studies of telemedicine interventions. BMJ 2002; 324(7351): 1434-1437. http://dx.doi.org/10.1136/bmj.324.7351.1434

16. Mistry H. Systematic review of studies of the cost-effectiveness of telemedicine and telecare. Changes in the economic evidence over twenty years. Journal of Telemedicine and Telecare 2012; 18(1): 1-6. http: //dx.doi.org/10.1258/jtt.2011.110505

17. Scuffham PA, Steed M. An economic evaluation of the Highlands and Islands teledentistry project. Journal of Telemedicine and Telecare 2002; 8(3): 165-177. http://dx.doi.org/10.1258/ 135763302320118915

18. Ologeanu-Taddei R, Bourdon I, Kimble C, Giraudeau N. The acceptability of teleconsultations in teledentistry: a case study. In: MM Cruz-Cunha (Ed). Encyclopedia of e-health and telemedicine. Hershey, USA: IGI Global, 2016; 1-12. http://dx.doi.org/ 10.4018/978-1-4666-9978-6.ch001

19. Davis FD, Bagozzi RP, Warshaw PR. User acceptance of computer technology: a comparison of two theoretical models. Management Science 1989; 35(8): 982-1003. http://dx.doi.org/ 10.1287/mnsc.35.8.982

20. Daniel SJ, Wu L, Kumar S. Teledentistry: a systematic review of clinical outcomes, utilization and costs. Journal of Dental Hygiene 2013; 87(6): 345-352.

21. Estai M, Kruger E, Tennant M. Perceptions of Australian dental practitioners about using telemedicine in dental practice. British Dental Journal 2016; 220(1): 25-29. http://dx.doi.org/10.1038/ sj.bdj.2016.25
22. Mandall NA, Quereshi U, Harvey L. Teledentistry for screening new patient orthodontic referrals. Part 2: GDP perception of the referral system. British Dental Journal 2005; 199(11): 727-729. http://dx.doi.org/10.1038/sj.bdj.4812969

23. Palmer NG, Yacyshyn JR, Northcott HC, Nebbe B, Major PW. Perceptions and attitudes of Canadian orthodontists regarding digital and electronic technology. American Journal of Orthodontics and Dentofacial Orthopedics 2005; 128(2): 163-167. http://dx.doi.org/ 10.1016/j.ajodo.2005.02.015

24. Flores-Mir C, Palmer NG, Northcott HC, Khurshed F, Major PW. Perceptions and attitudes of Canadian dentists toward digital and electronic technologies. Journal-Canadian Dental Association 2006; 72(3): 243.

25. Haron N, Zain RB, Nabillah WM, Saleh A, Kallarakkal TG, Ramanathan A, et al. Mobile phone imaging in low resource settings for early detection of oral cancer and concordance with clinical oral examination. Telemedicine Journal and e-Health 2016; epub 19 August.

26. Estai M, Kanagasingam Y, Xiao D, Vignarajan J, Bunt S, Kruger E, Tennant M. End-user acceptance of a cloud-based teledentistry system and Android phone app for remote screening for oral diseases. Journal of Telemedicine and Telecare 2015; epub 30 December.

27. Golder DT, Brennan KA. Practicing dentistry in the age of telemedicine. Journal of the American Dental Association 2000; 131(6): 734-744. http://dx.doi.org/10.14219/jada.archive.2000.0272

28. Daniel SJ, Kumar S. Teledentistry: a key component in access to care. Journal of Evidence Based Dental Practice 2014; 14: 201-208. http://dx.doi.org/10.1016/j.jebdp.2014.02.008

29. Patel RN, Antonarakis GS. Factors influencing the adoption and implementation of teledentistry in the UK, with a focus on orthodontics. Community Dentistry and Oral Epidemiology 2013; 41: 424-431. 